\title{
Preliminary Investigation on Sodium Alginate Extracted from Sargassum Subrepandum of Red Sea of Eritrea as Tablet Binder
}

\author{
N. S. Basha ${ }^{1 *}$, R. Rekha ${ }^{2}$, A. Letensie ${ }^{1}$, and S. Mensura ${ }^{1}$ \\ ${ }^{1}$ Department of Pharmaceutics, School of Pharmacy, Asmara College of Health Sciences, Asmara, \\ Eritrea, NE Africa \\ ${ }^{2}$ Department of Pharmacognosy, SRM College of Pharmacy, Kattangulathur, Chennai, Tamilnadu, India
}

Received 5 Jan 2011, accepted in revised form 18 May 2011

\begin{abstract}
Natural polysaccharides hold advantages over synthetic polymers for conventional and novel dosage forms, because these are non-toxic, less expensive, and biodegradable. These can also be modified to tailor-made materials and thus can compete with the available synthetic excipients. Therefore, the aim of present work is to extract sodium alginate from the seaweed $S$. subrepandum to assess its binding property using propranolol as model drug. Sodium alginate was extracted by room-temperature alkaline extraction and hightemperature $\left(80^{\circ} \mathrm{C}\right)$ alkaline extraction methods. Binding strength was evaluated by using two different formulations i.e., formulation 1 with sodium alginate as a binder and formulation 2 with hydroxypropylmethylcellulose (HPMC) as reference standard. The two tablet formulations were evaluated and compared for parameters such as friability, hardness and disintegration. The percentage yield was found to be $17.5 \% \mathrm{w} / \mathrm{w}$ by room-temperature alkaline extraction and $21 \% \mathrm{w} / \mathrm{w}$ by high-temperature extraction method. The results obtained for all tested parameters for tablets with sodium alginate were found within acceptable range of USP standards. It was also founded that both sodium alginate and HPMC have similar binding strength at similar concentration. So, it can be concluded that sodium alginate of $S$. subrepandum can be used as suitable alternative binder in tablet formulations.
\end{abstract}

Keywords: Sargassum subrepandum; Sodium alginate; Hydroxypropyl methylcellulose; Friability; Hardness; Disintegration.

(C) 2011 JSR Publications. ISSN: 2070-0237 (Print); 2070-0245 (Online). All rights reserved.

doi:10.3329/jsr.v3i3.6770 J. Sci. Res. 3 (3), 609-618 (2011)

\section{Introduction}

Marine organisms are a rich source of structurally most diverse and abundant, novel and biologically active metabolite that might represent useful leads in the development of new pharmaceutical agents. Among the marine organisms, interest in isolating new bioactive compounds from marine algae is now increasing tremendously [1]. Algae can be classified into two main groups; first one is the microalgae, which includes blue-green

\footnotetext{
*Corresponding author: nsaleem_basha@rediffmail.com
} 
algae, dinoflagellates, bacillariophyta (diatoms) etc. and second one is macroalgae (sea weeds) which includes green, brown and red algae. The principal use of sea weeds as a source of human food and as a source of gums (phycocolloides). Phycocolloides like agaragar; alginic acid and carrageenan are primarily constituents of brown and red algal cell walls and are widely used in industry [2]. Investigators have studied various activities of seaweeds and have found that the seaweeds have not only nutritional effects but also beneficial properties to cure various diseases and maintain good health [3]. In recent years, the biomedical and pharmaceutical industries have shown much increased interest in the use of biopolymers, particularly alginates [4]. Algal polysaccharides have been widely accepted to be one of the important candidates for the development of effective and non- toxic medicines with stronger free radical scavenging and antioxidant action [5] and Reno protective effect [6].

Alginates are known as one of the natural binder, the main advantages of natural polymers lie in their biocompatibility and biodegradability, without producing systemic toxicity on administration [7]. Sodium alginate is used in a variety of oral and topical pharmaceutical formulations. In tablet formulation, it may be used as both a binder and disintegrators; It has also been used the preparation of sustained-release oral formulations $[8,9]$. In topical formulations, sodium alginate is widely used as a thickening and suspending agent in a variety of pastes, creams, and gels, and as a stabilizing agent for oilin-water emulsions [10]. Sodium alginate is reported to be a useful adjuvant in immunization against two strains of influenza virus, and in treatment of esophagitis. Alginate has been recognized as a suitable biopolymer for protein drug delivery, due to possessing various desirable characteristics. These include suitable biodegradability, ease of ability to prepare micro and nanospheres, mucoadhesive nature and adhesion to the epithelial cells, and relatively high loading capacity for proteins [11, 12].

Sodium alginate was also used as artificial skin in healing of skin graft donor sites [13]. Sulfated polysaccharides, including natural and synthesized ones, had great bloodcompatibility or even anticoagulant activity [14]. A recent study demonstrated that low molecular mass potassium alginate (L-PA), one of the major polysaccharides extracted from brown algae, decreased systolic blood pressure (SBP) in spontaneous hypertensive rats [15]. Calcium cross linked sodium alginate has been implanted in both animals and humans and calcium cross linked sodium alginate is widely used as a haemostatic wound dressing material [16].

Sargassum spp is one of the major sources for sodium alginate. The algae are named for the Atlantic Ocean's Sargasso Sea, which hosts a large amount of several species of Sargassum. Sargassum subrepandum is one of the Sargassum Sp. Class: Phaeophyceae, Order: Fucales, Family: Sargassaceae, Genus: Sargassum, Species: subrepandum, Scientific name: - Sargassum subrepandum, Unambiguous synonym: Fucus subrepandum. It is widely distributed in Africa (Eritrea, Ethiopia, Egypt, and Sudan etc), Indian Ocean islands and south-west Asia (Jordan, Saudi Arabia) [17].

Most, if not all, of the pharmaceutical raw materials that are used by the pharmaceutical plant in Eritrea are being imported from other countries. For instance 
HPMC is one of the commonly used binders but it is expensive. Therefore researches should be done on the natural products of Eritrea to take an advantage as a source of raw materials and to avoid expenses.

Literature survey could not reveal the effect of sodium alginate from S. subrepandum as tablet binder and hence the present study is aimed to extract sodium alginate from $S$. subrepandum by using two methods, e.g., high temperature alkaline extraction and room temperature alkaline extraction. Further we investigate its binding efficiency using model drug propranolol in optimum formulation and comparison with a standard binder, hydroxypropyl methylcellulose (HPMC) using various parameters like the crushing strength, friability and disintegration time. Since there is no report on sodium alginate from $S$. subrepandum, there is a great opportunity to discover new compounds from these species.

\section{Materials and Methods}

\subsection{Materials used}

AE240 analytical balance (Mettler), 1501 MP8 bench top balance (Sartorius), Vander Kamp friabilator (Vankel Industries Inc), Schleuniger - 2 E hardness tester (Germany), B3B multi punch tablet press (Manesty, Great Britain), PTZ3E disintegration tester (Pharma test), N-50 wet-granulator (Hobart), 213023-15 oven (Supermatecl), water bath, thermometer, mortar and pestle, sieve number $=20$, beaker and volumetric flask, stirrer, filter pump and muslin cloth.

\subsection{Chemicals used}

Distilled water, $0.2 \mathrm{~N}$ hydrochloric acid, 2\% w/w sodium carbonate, 99.7-100\% ethanol, hydroxy propyl methyl cellulose (HPMC), microcrystalline ph 102 (MCC), propranolol, magnesium stearate and sodium alginate from $S$. subrepandum.

\subsection{Collection of seaweed}

An identified S. subrepandum (seaweed) which was collected from Massawa (Red sea) was obtained as a gift sample from medicinal plant drug discovery research centre (MPDDRC), Asmara, Eritrea. Then the plant materials were grinded to coarse powder by using electric grinder and preserved for sodium alginate extraction with respective solvents.

\subsection{Extraction of sodium alginate}

Sodium alginate was extracted from the seaweed, $S$. subrepandum, by two methods, (i) room temperature alkaline extraction and (ii) high temperature alkaline extraction [18]. 


\subsubsection{Room temperature alkaline extraction method}

$2 \mathrm{~g}$ of dried and grinded materials of $S$. subrepandum was taken. To the above plant material, $50 \mathrm{ml}$ of $2 \% \mathrm{w} / \mathrm{w}$ sodium carbonate was added and stirred. The mixture obtained was allowed to stand for two hours and then filtered using muslin cloth. To the filtrate obtained above step, $75 \mathrm{ml}$ of $0.2 \mathrm{~N}$ hydrochloric acid was added and stirred well. Insoluble alginic acid was formed. Then the mixture obtained was filtered and the resulting residue was dried to obtain alginic acid. To the alginic acid obtained from the above step, excess of $2 \% \mathrm{w} / \mathrm{w}$ sodium carbonate solution was added at which sodium alginate was formed. To the obtained solution equal volume of ethanol was added to precipitate sodium alginate. Then the mixture was filtered and the precipitate was allowed to dry at room temperature and dry weight was taken to determine the percentage yield.

\subsubsection{High- temperature $\left(80^{\circ} \mathrm{C}\right)$ alkaline extraction}

$2 \mathrm{~g}$ of dried and grinded materials of $S$. subrepandum was taken and washed with $15 \mathrm{ml}$ of $0.2 \mathrm{~N}$ hydrochloric acid. The obtained mixture was filtered and the residue was washed with distilled water. Then $50 \mathrm{ml}$ of $2 \% \mathrm{w} / \mathrm{w}$ sodium carbonate solution was added to the solid residue little by little while heating at $80^{\circ} \mathrm{C}$ and constantly stirring it for two hours. The obtained mixture was then allowed to cool and filtered. To the filtrate $75 \mathrm{ml}$ of $0.2 \mathrm{~N}$ hydrochloric acid was added little by little. Formation of insoluble alginic acid was occurred. The mixture was filtered and the residue dried to obtain alginic acid. Excess of $2 \% \mathrm{w} / \mathrm{w}$, sodium carbonate was added to the alginic acid obtained in the above step at which formation of sodium alginate was occurred. Finally equal volume of ethanol was added to the solution to precipitate sodium alginate. The mixture was filtered. The precipitate obtained was allowed to dry at room temperature and dry weight was taken to determine the percentage yield. The percentage yield was calculated by using the formula: Percentage yield $=$ weight of dry sodium alginate/ weight of sargassum powder $\times 100$.

\subsection{Preparation of tablet formulations}

Two types of tablets were formulated and named as formulation 1 and formulation 2 . Tablet formulation 1 contains $10 \mathrm{mg}$ propranolol with sodium alginate extracted from $S$. subrepandum as a binder; tablet formulation 2 contains 10mg propranolol with HPMC as

Table 1. Tablet composition of formulation 1.

\begin{tabular}{lc}
\hline Ingredients & $\% \mathrm{w} / \mathrm{w}$ \\
\hline Propranolol & 20 \\
Sodium alginate & 2 \\
Croscaramellose sodium & 2 \\
Magnesium stearate & 0.3 \\
Microcrystalline cellulose & 75.7 \\
\hline
\end{tabular}


Table 2. Tablet composition of formulation 2.

\begin{tabular}{lc}
\hline Ingredients & \% w/w \\
\hline Propranolol & 20 \\
Hydro propyl methyl cellulose & 2 \\
Croscaramellose sodium & 2 \\
Magnesium stearate & 0.3 \\
Microcrystalline cellulose & 75.7 \\
\hline
\end{tabular}

a binder. The concentration of other excipients remains the same for both the formulations. Tablets of formulation 1 and formulation 2 were prepared by wet granulation method. Composition of formulation 1 and formulation 2 are given in Table 1 and Table 2. The tablet formulations were carried out as in following sections.

\subsubsection{Wet granulation}

$20 \mathrm{~g}$ of propranolol (active ingredient) was mixed with 75.5g of microcrystalline cellulose (diluents) and $1 \mathrm{~g}$ of croscaramellose sodium (disintergrant) manually until a uniform mass was obtained. The mixture was granulated using mechanical powder blender while adding $6.2 \mathrm{ml}$ of $3.2 \mathrm{w} / \mathrm{v}$ aqueous solution of sodium alginate (binder) extracted from $S$. subrepandum little by little. The obtained wet granules were spread evenly on large piece of paper in shallow tray and dried in oven at $60^{\circ} \mathrm{C}$ for three hours. The dry granules were pressed through sieve (number $=20$ ) by hand to obtain granules of the uniform size. Finally one gram of croscaramellose sodium and $0.3 \mathrm{~g}$ of magnesium stearate (lubricant) were added to the granules and blended until uniform mixture was obtained [19].

\subsubsection{Tablet compression}

The mixed granules obtained by wet granulation were then compressed into tablets. Target tablet weights were $500 \mathrm{mg}$ for propranolol. The granules were compressed manually by using B3B multi punch tablet press (Manesty, Great Britain) fitted with a concave punch and die set with die size of 11 millimetres. Wet granulation and tablet compression were carried out for formulation 2 using the same procedure followed for formulation 1 except HPMC was used as a binder instead of sodium alginate. The compressed tablets of each batch were stored in air tight container at room temperature for further study.

\subsection{Evaluation of binding properties of sodium alginate}

Tablets properties which can be influenced by binder were tested for all prepared tablets containing sodium alginate as a binder and hydroxypropyl methyl cellulose (HPMC) as binder. To point out binder influence on the properties of tablets, response variables 
such as tablet hardness (H), friability (Fr), and disintegration time (DT) were selected. All the tests were done according to USP standard [20].

\subsubsection{Friability test}

Friability of randomly selected (mean $\pm \mathrm{SD}, n=10$ ) tablets of total weight $6.562 \mathrm{~g}$ (initial weight) were taken from formulation 1, placed in the acnylic drum of a Vander Kamp friabilator (Vankel Industries Inc). Tablets were subjected to combined effects of abrasion and shock by allowed to roll and fall with in the drum at 25 revolutions per minute for 100 revolutions. The tablets were removed from the friabilator, dedusted and weighed (final weight). This procedure was repeated three times by taking other tablets from the same formulation, the initial weight, final weight and weight loss were recorded as friability. The percentage weight loss was calculated as:

$$
\% \text { weight loss }=\frac{\text { (Initial weight }- \text { final weight })}{\text { Initial weight }} \times 100 \text {. }
$$

Friability test was done for formulation-2 by the same procedure followed for formulation 1.

\subsubsection{Hardness test}

The hardness of the tablets (mean $\pm \mathrm{SD}, n=10$ ) was examined by taking tablets with not much difference in weight i.e. $500 \mathrm{mg} \pm 5$. Tablets were taken from formulation 1 , each tablet was placed in the Schleuniger $-2 \mathrm{E}$ hardness tester (Germany) on its edge. The machine was allowed to crush the tablet and the force required to crush the tablet was recorded in kilo pond (KP). Hardness test was done for formulation 2 by the same procedure was followed for formulation 1.

\subsubsection{Disintegration test}

Disintegration test was carried out according to USP specification. 6 randomly selected tablets from formulation-1 were placed in a PTZ3E disintegration tester (Pharma test). The beaker, for the immersion fluid, of the disintegration tester was filled with 900 millilitres distilled water. All tablets were allowed to enter in to the tubes at the same time while the basket rack assembly was allowed to move up and down. A thermostatic arrangement for heating the fluid to $37^{0} \mathrm{C}$ was made.

The basket was maintained to raise and lower in the immersion fluid at 29 cycles per minute. At the highest point of the upward stroke the wire mesh was maintained to remain at 2.5centimeter below the surface of the fluid and descends to 2.5 centimeter from the bottom of the vessel on the down ward stroke. The time required for complete disintegration of the tablets was recorded in triplicates. The tablets were considered completely disintegrated when all the particles passed through the wire mesh. 
Disintegration test was done for formulation-2 tablets by the same procedure followed for formulation-1.

\section{Results and Discussion}

The extracted sodium alginate had pungent smell (fish smell) and was deep brown-black in colour. The percentage yield of sodium alginate was found to be $17.5 \% \mathrm{w} / \mathrm{w}$ and 21 $\% \mathrm{w} / \mathrm{w}$ by room temperature alkaline extraction and by high temperature alkaline extraction method which was comparable with the yield from other species of Sargassum of other countries, i.e., 21\%w/w, 25\%w/w and 11.5-22.5\%w/w in southern coast of Brazil, India and Peurto Rico, respectively [21, 22]. From the two methods used to extract sodium alginate, the high yield was obtained from high temperature-alkaline extraction compared to room temperature-alkaline extraction method. Hence this method was used for the mass extraction of sodium alginate. Sodium alginate extracted from $S$. subrepandun was shown in Fig. 1, tablets with sodium alginate as binder were shown in Fig. 2 and tablets with HPMC as a binder were shown in Fig. 3.

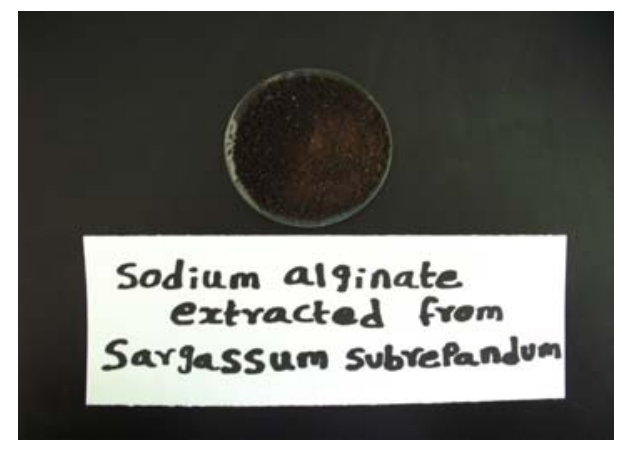

Fig. 1. Sodium alginate extracted from Sargassum subrepandum.

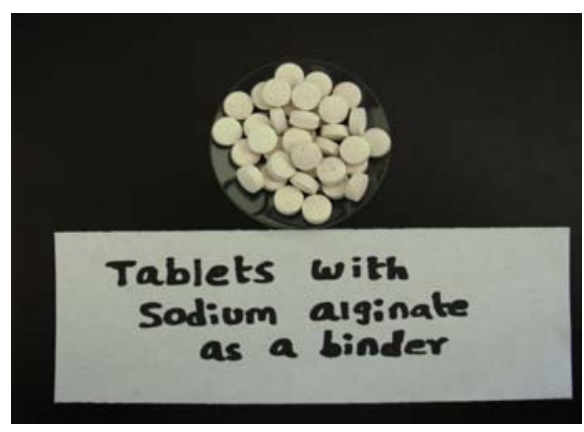

Fig. 2. Tablets with sodium alginate.

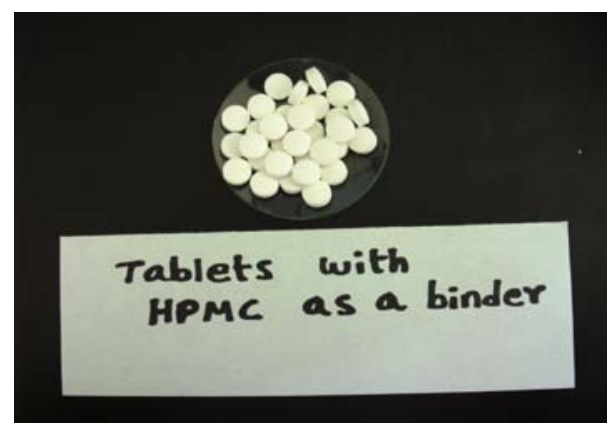

Fig. 3. Tablets with HPMC. 
From the results of various evaluation tests preformed on formulation 1 and formulation 2, it was observed that the tablets containing alginate as a binder showed similar/comparable properties (friability, hardness and disintegration) with the tablets containing HPMC as a binder. However, tablets containing sodium alginate were less friable and harder than tablets containing HPMC. In the friability tests, friability values were less than $1 \%$ for all both the formulations 1 and 2 . The results of friability test, hardness test and disintegration test for formulation 1 and formulation 2 were shown in Table 3.

Table 3. Evaluations of tablets.

\begin{tabular}{cccc}
\hline $\begin{array}{c}\text { Formulation } \\
\text { type }\end{array}$ & $\begin{array}{c}\text { Hardness } \\
\text { (kp) }\end{array}$ & $\begin{array}{c}\text { Friability } \\
\text { (\%weight loss) }\end{array}$ & $\begin{array}{c}\text { Disintegration } \\
\text { (time in min) }\end{array}$ \\
\hline 1 & $6.11 \pm 0.363$ & $0.273 \pm 0.006$ & $28.3 \pm 0.577$ \\
2 & $5.17 \pm 0.216$ & $0.343 \pm 0.006$ & $23.66 \pm 0.577$ \\
\hline
\end{tabular}

The results of hardness test showed that addition of sodium alginate improved cohesion during the granulation operations to enlarge the particle size of granules and also during compression to increase the hardness of tablets. The binding ability of salginate resulted in stronger adhesion between granules. Whereas croscaramellose sodium, magnesium stearate and microcrystalline cellulose included in the formulations were expected to enhance flow ability and compressibility.

In case of disintegration tests, the tablets of both formulations 1 and 2 disintegrated within 30 seconds. From the result obtained, formulations containing sodium alginate as a binder showed a slower onset of disintegration time than those containing HPMC and compared favourably with the standard HPMC as a binder.

The present study indicated that sodium alginate can be used as binding agent along with croscaramellose sodium, magnesium stearate and microcrystalline cellulose. Furthermore, addition of sodium alginate with propranolol fulfilled the hardness, friability and disintegration criteria. This indicated that there shall not be any problem while formulating tablet dosage form using sodium alginate derived from S. subrepandum and hence it could be a useful substitute binder in propranolol tablet formulations with good physical properties.

\section{Conclusion}

Plants provide an attractive and renewable source not only for active pharmaceutical ingredients but also for materials that can be utilised as excipients in pharmaceutical products for the effective delivery of drugs [23]. Compressed tablets are the most widely used of all Pharmaceutical dosage forms for a number of reasons. They are convenient, easy to use, portable and less expensive than other oral dosage forms. Selection of excipients is critical in tablets. One of the important excipients used in the tablets is binder. Binders are the "glue" that holds powders together to form granules. Tablets containing sodium alginate extracted from $S$. subrepandum as a binder showed acceptable properties and also compares favourably with the standard binder HPMC used. 
It is evident from the present study that the S. subrepandum could be utilized as a good natural source of binders in pharmaceutical industry. Further detailed studies should be done on other Sargassum species of red sea (Eritrea) for their content and yield of alginate, and to optimize the binder concentration. Alginate from S. subrepandum of Red sea (Eritrea) should be studied for other possible applications such as complexation of metal ions and to construct drug carriers for novel drug delivery systems, biotechnological applications and other delivery systems.

Since the Eritrean seaweed resources are still untouched, calls on an intensive study and wise utilization of such resources should be put into focus and consideration. It could be recommended that there is a need for a general biomass study of seaweed resources to determine the maximum sustainable yield and also to study the possible means of artificial propagation, processing methods in relation to seasonality. Such studies would synchronize with other ongoing efforts, on neighbouring countries, to unveil the Red Sea rich resources. Also, a major conclusion can be derived on the basis of above experiment that sodium alginate which is a polymer of natural origin, has immense potential to replace the commercially existing expensive polymers as binders in tablet dosage forms.

\section{Acknowledgement}

The authors are thankful to Dr. Azeib Ogbaghebriel, Dean, Asmara College of Health Sciences, Asmara, Eritrea, North East Africa. It is our great pleasure to express our thanks to Mr. Embaye Tekabo (administrator), Mr. Teame Zeratsion and Mr. Tesfay Hagos members of the MEGA pharmaceuticals for their guidance during the experimental procedures and for providing necessary facilities to carry out the present research work.

\section{References}

1. J. T. Anggadiredja, Proc. Sem. Rip. Kela. Nas. IKN 78-89 (1998).

2. Ali A. El Gamal, S. Pharm. J. 18 (1), 1 (2010).

3. J. Carper, The Food Pharmacy, (Bantam Books, New York, 1989).

4. A. Shilpa, S. S. Agrawal, A. R. Ray, and J. Macromol. Sci. Polym. Rev. C43, 187 (2003).

5. Q. Zhang, N. Li, X. Liu, and Z. Zhao, Carbohyd. Res. 339, 105 (2004). doi:10.1016/j.carres.2003.09.015

6. Q. Zhang, Z. Li, Z. Xu, X. Niu, and H. Zhang, Plan. Med. 69, 537 (2003). doi:10.1055/s-2003-38490

7. S. Takka and F. Acarturk, J. Microencap. 16, 275 (1999).

8. Alginates for Pharmaceutical and medical applications, Product guide: ISP Pharmaceuticals. http://www.iscorp.com.

9. Handbook of pharmaceutical excipients, $4^{\text {th }}$ edition (American Pharmaceutical Association and Pharmaceutical press, Washington, 2003).

10. B. M. Mithal, A text book of Pharmaceutical formulation, $6^{\text {th }}$ edition (Vallabh prakashan, Delhi, 1997).

11. G. Jiang, S. Min, E. J. Oh, and S. K. Hahn, Biotech. Biopro. Eng. 12, 684 (2007). doi:10.1007/BF02931086

12. A. R. Mokarram and M. J. Alonso, Arch. Razi. Inst. 61, 13 (2006).

13. P. Vanstraelen, J. of. Bur. 18, 145 (2000). doi:10.1016/0305-4179(92)90014-L

14. S. Alban, A. Schauerte, and G. Franz, Carbohyd. Poly. 47, 267 (2002). doi:10.1016/S0144-8617(01)00178-3

15. W. Ji, Y. Y. Chen, J. R. Du, D. K. Yu, X. Y. Zheng, and F. Yang, J. Sichuan. Univ. (Medical Science Edition), 40, 694 (2009). 
16. I. R. Matthew, R. M. Browne, J. W. Frame, and B. G. Millar, Biomater. 6, 275 (1995). doi:10.1016/0142-9612(95)93254-B

17. Coastal and Marine life: Protoctista: Algae: Brown algae; Marine and coastal management, Department of Environmental affairs and tourism, South Africa. http://www.saccasi.wcape.gov.za; http://www.algaebase.org

18. T. A. Davis, M. Ramirez, A. Mucci, and B. Larsen, J. appl. phyco. 16, 275 (2004).

19. G. S. Bankar and R. A. Neil, Theory and practice of industrial pharmacy, L. Lachman, A. H. Lieberman and L. K. Joseph (ed.) $3^{\text {rd }}$ edition (Varghese publishers, Mumbai, 1987).

20. United States pharmacopoeia 23/National Formulary 18. United States Pharmacopoeia convention, INC (1995).

21. S. J. Saraswathi, B. Babu, and R. Rengasamy, Phycol. Res. 51, 240 (2003). doi:10.1111/j.1440-1835.2003.tb00191.x

22. S. Istnini, M. Ohno, and H. Kusunose, Bull. Mar. scl. Fish. 14, 49 (1994).

23. T. Aklilu, Ph. D Thesis, ADDIS ABABA University, Ethiopia (June 2002). 